during Test 1 may have been one factor responsible. Though Kivy et al (1956) failed to find significant response to change with 1-min exposure, it has been found with exposures of 2 to $3 \mathrm{~min}$ (Dember \& Millbrook, 1956; Fowler, 1958) in mazes which permitted $S$ to remove himself from the relevant stimuli at the choice point. The present design did not permit ordinary position or brightness preferences to play a role which could depress response to change below $50 \%$. However, it is possible that the percentages below chance were not merely a result of random processes and that they, and the generally low level of response to change, were due to a systematic and uncontrolled factor. With one exception, the side changed (or changed most) on Trial 2 was the lightest side on Trial 1 for all conditions. If a temporary preference for the darker side developed during Trial 1 , and this same side preference continued through Trial 2, when brightness was uniform, a depression of response to change would have resulted.

Though not all reports of previous studies on response to brightness change in $\mathrm{T}$ - or $\mathrm{Y}$-mazes are complete in their definitions of the choice criterion, these studies apparently al used the entry measure (Dember, 1965; Dember \& Millbrook, 1956 Fowler, 1958; Kivy et al; 1956 Levine, 1958; Levine, Staats, \& Frommer, 1958; Woods \& Jennings, 1959). In the present study, the entry and final choice measures did not differ significantly on either test however, the entry measure showed high consistency in tests separated by several months and with different exposure durations. The condition order which displayed this consistency was, from greater to lesser choice of the changed side: Conditions $6,8,1$ through 5, 7. The absence of consistent or appropriate differences among Conditions 1-5 does not encourage scaling attempts under the conditions used in this study. The latency data did not show sufficient regularity to be interpretable.

REFERENCES

DEMBER, W. N. Response by the rat to environmental change. Journal of Comparative \& Physiological Psycholody, $1956,49,93-95$.

DEMBER, W. N., \& MILLBROOK, B. A. Free-choice by the rat of the greater of two brightness changes. Psychological Reports, $1956,2,465-467$.

FOWLER, H. Response to environmental change: A positive replication. Psychological Reports, 1958, 4, 506.

KIVY, P. N., EARL, R. W., \& WALKER, E. L. Stimulus context and satiation. Journal of Comparative \& Physiological Psychology, 1956, 49, 90-92.

LEVINE, S. A reply to a comment by Dember. Psychological Reports, 1958, 4 433 .
LEVINE, S., STAATS, S. R., \& FROMMER, G. Studies on "Response by the rat to environmental change," Psychological Reports, 1958, 4, 139-144.

O'CONNELL, R. H. Comparison of alternation and response to stimulus change. Journal of Comparative \& Physiological Psychology, 1964, 57,
362-366.

WINER, B. J. Statistical principles in experimental design. New York: McGraw-Hill, 1962.

WOODS, P. J., \& JENNINGS, S. Response to environmental change: A further confirmation. Psychological Reports, $1959,5,560$

\title{
Failure to find polydipsia in isolation-reared monkeys*
}

\author{
N. A. FITTINGHOFF, JR., D. G. LINDBURG, and G. MITCHELL† \\ National Center for Primate Biology, Davis, Calif. 95616
}

The water consumption of six adult male monkeys, reared in social isolation, was compared with that of five feral-reared controls. Isolate polydipsia, reported elsewhere, was not found in the present study.

Miller et al (1969) reported that three monkeys (Macaca mulatta) which had spent their first 12 months of life in total social isolation displayed polydipsia when they were approximately 5 years old. The three isolates they observed, one female and two males, drank "approximately twice as much fluid" as "three feral males of approximately the same size and age [p. 1027]." The polydipsia of their three isolates was marked and fairly uniform.

In a pilot study conducted by one of the present authors, eight four- and five-year-old isolates drank (on the average) nearly twice as much water over a 24-h period as eight

* This research was supported by National Institutes of Health Grants MH17425, FR00169, and HD04335, as well as by University of California, Davis, Faculty Research Grants D-552 and D-515.

$+N$. A. Fittinghoff, $J r .$, and D. G. $L$ indburg are in the Department of Anthropology and $G$. Mitchell is in the Department of Psychology at the University of California, Davis, California 95616. mother-peer-raised laboratory controls (see Mirsky, 1968, p. 116). The variability from isolate to isolate was substantial, and there was considerable overlap between the isolate and control groups. Thus, the Miller et al results and our own results were suggestive enough to attempt to replicate with different isolates.

\section{SUBJECTS}

Six wire-cage-reared (socially isolated) adult male rhesus monkeys (Macaca mulatta $)^{1}$ and five wild-reared adult male rhesus monkeys were used as Ss. One isolate male was 4 years, $81 / 2$ months old, while the other five were 12 and 13 years old. The exact ages of the controls are unknown, but their outside age limits are 6 and 10 years of age.

The isolates were born at the University of Wisconsin primate laboratories and were separated from their mothers within $24 \mathrm{~h}$ of birth. Though they were not raised in enclosed cages (total isolation), none was permitted other than visual and aural contact with another monkey
ERRATUM

LEVINSON, HOTTMAN AND SHERIDAN Assessment of the generality of enhanced learning following unilateral lesions of posterior neocortex in rats Psychonomic Science, 1971, Vol. 22 (1) 1-3. "Because of the difficulty in determining the extent of brain lesions from the photographs presented in the article, the authors have made additional copies of the originial photographs and will distribute them upon request." 
Table 1

Water Consumption During Five 8 -h Days (Liters Consumed/kg of Body Weight)

\begin{tabular}{|c|c|c|c|c|c|c|c|c|c|c|c|}
\hline & \multicolumn{5}{|c|}{ Controls } & \multicolumn{6}{|c|}{ Isolates } \\
\hline & A & $\mathbf{B}$ & $\mathbf{C}$ & $\mathbf{D}$ & $\mathrm{E}$ & 1 & 2 & 3 & 4 & 5 & 6 \\
\hline Total consumption (Ls) & 4.464 & 10.543 & 4.659 & 1.997 & 6.574 & 6.630 & 3.825 & 8.205 & 6.461 & 2.226 & 9.411 \\
\hline Body weight $(\mathrm{kg})$ & 11.40 & 14.10 & 12.28 & 9.12 & 12.06 & 11.22 & 9.07 & 10.27 & 9.83 & 8.24 & 7.72 \\
\hline $\mathrm{Ls} / \mathbf{k g}$ & 0.391 & 0.748 & 0.379 & 0.219 & 0.545 & 0.591 & 0.422 & 0.799 & 0.657 & 0.270 & 1.219 \\
\hline
\end{tabular}

Table 2

Water Consumption During Five 8-h and Three 24-h Days (Ranks of Liters Consumed/kg of Body Weight)

\begin{tabular}{|c|c|c|c|c|c|c|c|c|c|c|c|c|c|}
\hline & \multicolumn{6}{|c|}{ Controls } & \multicolumn{7}{|c|}{ Isolates } \\
\hline & $\mathbf{A}$ & $\mathbf{B}$ & $\mathrm{C}$ & $\mathbf{D}$ & $\mathbf{E}$ & $\begin{array}{c}\text { Sum of } \\
\text { Ranks }\end{array}$ & 1 & 2 & 3 & 4 & 5 & 6 & $\begin{array}{c}\text { Sum of } \\
\text { Ranks }\end{array}$ \\
\hline $\begin{array}{c}\text { 8-h } \\
\text { rank }\end{array}$ & 8 & 3 & 9 & 11 & 6 & 37 & 5 & 7 & 2 & 4 & 10 & 1 & 29 \\
\hline $\begin{array}{l}\text { 24-h } \\
\text { rank }\end{array}$ & 7 & 2 & 8 & 10 & 5 & 32 & 6 & 9 & 4 & 3 & 11 & 1 & 34 \\
\hline
\end{tabular}

before the eighth month of life. The five older animals subsequently took part in a number of psychological experiments, and all five received social experience before age 6-in a two-animal cage, on a monkey island, or, with one exception, in both these ways. The youngest animal had received no such experience at the time of the present study. During the study, all the isolates displayed one or more behavioral abnormalities, e.g., self-slapping, self-biting, "floating" limbs, rocking, swaying, or other stereotyped whole-body movements. None of the control animals behaved abnormally.

APPARATUS AND REGIMEN

Both groups were maintained in the same climate-controlled room in individual home cages at the National Center for Primate Biology in Davis, Calif. The daily food ration for each animal was $30-40$ Purina monkey pellets, half provided at $7: 30 \mathrm{a} . \mathrm{m}$. and half at 3:00 p.m. In addition, each animal received fresh oranges once a week. Tap water was supplied from inverted bottles fitted with metal drinking tubes; to obtain water the monkeys were required to suck on the tubes.

\section{PROCEDURE}

Each monkey was furnished $900 \mathrm{ml}$ of water at 8:30 a.m. on each day of the study, which lasted for 5 days per monkey. The water level of each bottle was checked hourly, and the bottle was refilled to $900 \mathrm{ml}$ whenever it was found empty (usually once or twice in 8 daylight hours). Each monkey's total consumption for the period between $8: 30$ a.m. and $4: 30$ p.m. was recorded for the 5 days. Since the 11 monkeys ranged in weight from 7.72 to $14.10 \mathrm{~kg}$, the 5-day consumption of each was divided by body weight to obtain total consumption/kilogram. During the last 3 days of the study, 24-h consumption was also measured. The raw data for each $S$ (in milliliters per kilogram) were used in comparing the two groups. One-tailed Student's $t$ and Mann-Whitney $U$ tests were used for the comparison.

\section{RESULTS}

Table 1 summarizes the calculations for the 8:30 a.m. to $4: 30$ p.m. intervals.

The mean consumption for the isolates was $660 \mathrm{ml} / \mathrm{kg}$; for the controls it was $456 \mathrm{ml} / \mathrm{kg}$. Neither statistic was significant at the .05 level $(\mathrm{t}=1.28, \mathrm{U}=8)$.

Table 2 compares the two groups and the 8 - and 24 -h periods. The lower the rank integer in Table 2 , the greater the consumption/kilogram. The table indicates that each monkey's daytime drinking rank prevailed in essence around the clock.

\section{DISCUSSION}

This study falls short of supporting the Miller et al (1969) data and our own pilot data. Though unexpected, the result does not appear due to experimental error. A review of the raw data reveals that, on each of 3 different days, a different isolate emptied his bottle between $3: 30$ and 4:30 p.m. Presumably each of the three animals would have drunk more during this hour if more had been available. Relative to the entire study, however, this source of error is minor and largely offset by two similar occurrences among the controls.

The source of the discrepancy is difficult to locate precisely. For the 3 days during which we recorded $24-\mathrm{h}$ consumption, the mean daily consumption of our isolates was 1.607 liters/animal $(175 \mathrm{ml} / \mathrm{kg})$. The mean daily consumption of our controls was 1.648 liters/animal $(135 \mathrm{ml} / \mathrm{kg})$. By contrast, the mean daily consumption of the isolates in the Miller et al study seems to have been below 1.3 liters/animal, and the mean daily consumption of the controls, below 0.5 liter/animal. ${ }^{2}$ Therefore, if one compares studies, the behavioral variation between control groups greatly exceeds that between isolate groups. In the present study, however, within-group variation in water consumption was considerable for both controls and isolates and was greater for isolates. ${ }^{3}$ Thus, it appears that the difference in water consumption between wild-reared and isolation-reared monkeys is less clearcut, overall, than previous studies have suggested.

There is a possible explanation for the unexpected result obtained here. The difference may lie in the relative ages of the animals. In the present study, the controls were between 6 and 10 years old. All the isolates, except No. 6, were between 12 and 13 years old. No. 6 was 4 years, $81 \frac{1}{2}$ months old, much closer in age to the three isolates of Miller et al than were the other five isolates. It is interesting that No. 6 also consumed the most water. Perhaps isolate polydipsia wanes during adult life. Reasons for the occurrence of polydipsia must wait for the firm demonstration that it does, in fact, exist because of early isolation.

\section{REFERENCES}

MILLER, R. E., MIRSKY, I. A., CAUL, W. F., \& SAKATA, T. Hyperphagia and polydipsia in socially isolated rhesus monkeys. Science, $1969,165$. 1027-1028.

MIRSKY, I. A. Discussion (of scope and potential of primate research, by $W$. A. Mason). Science \& Psychoanalysis, 1968, 12,112-118.

1. We wish to thank Dr. H. F. Harlow for supplying us with the isolates used in this study.

2. Figures were approximated by interpreting the bar graph of Fig. 1, p. 1027. in Miller et al (1969).

3. Ranges of mean daily consumptions were as follows: Five controls: $0.821-2.881$ liters/animal (90-204 ml $/ \mathrm{kg})$; six isolates: $0.633-2.764$ liters/animal $(77-358 \mathrm{ml} / \mathrm{kg})$. 